OPEN ACCESS

Edited by:

Xin Chen,

University of Macau, Macau

Reviewed by:

Chun-Yen Lin,

Chang Gung Memorial

Hospital, Taiwan

Yogesh Singh,

Universität Tübingen, Germany

${ }^{*}$ Correspondence:

Zhihai Qin

zhihai@ibp.ac.cn

Specialty section:

This article was submitted

to Immunological Tolerance

and Regulation,

a section of the journal

Frontiers in Immunology

Received: 02 March 2018

Accepted: 09 May 2018

Published: 28 May 2018

Citation:

Sheng Y, Li F and Qin Z (2018) TNF Receptor 2 Makes Tumor Necrosis

Factor a Friend of Tumors.

Front. Immunol. 9:1170.

doi: 10.3389/fimmu.2018.01170

\section{TNF Receptor 2 Makes Tumor Necrosis Factor a Friend of Tumors}

\author{
Yuqiao Sheng', Feng $L^{2}{ }^{2}$ and Zhihai Qin ${ }^{1 *}$ \\ ${ }^{1}$ Medical Research Center, The First Affiliated Hospital of Zhengzhou University, Zhengzhou, China, ${ }^{2}$ Biotherapy Center, \\ The First Affiliated Hospital of Zhengzhou University, Zhengzhou, China
}

Tumor necrosis factor (TNF) is widely accepted as a tumor-suppressive cytokine via its ubiquitous receptor TNF receptor 1 (TNFR1). The other receptor, TNFR2, is not only expressed on some tumor cells but also on suppressive immune cells, including regulatory $T$ cells and myeloid-derived suppressor cells. In contrast to TNFR1, TNFR2 diverts the tumor-inhibiting TNF into a tumor-advocating factor. TNFR2 directly promotes the proliferation of some kinds of tumor cells. Also activating immunosuppressive cells, it supports immune escape and tumor development. Hence, TNFR2 may represent a potential target of cancer therapy. Here, we focus on expression and role of TNFR2 in the tumor microenvironment. We summarize the recent progress in understanding how TNFR2-dependent mechanisms promote carcinogenesis and tumor growth and discuss the potential value of TNFR2 in cancer treatment.

Keywords: tumor necrosis factor, TNF receptor 2, tumor, myeloid-derived suppressor cells, regulatory T cells, macrophages

\section{INTRODUCTION}

The $34 \mathrm{kDa}$ pleiotropic cytokine tumor necrosis factor (TNF) is a type II transmembrane protein important in carcinogenesis, cancer progression, and metastasis, as well as in immunity (1-3). Connecting a wide variety of cell types, TNF constitutes itself a central player in the multi-faceted tumor microenvironment. TNF can exert both tumor-promoting and -suppressing roles, and those distinct effects are transmitted by two receptors, TNF receptor 1 (TNFR1) and TNFR2 (4-8). Although the role of TNFR2 is less well understood, many reports indicated it as crucial in tumors (Table 1). This review does not aim to give all details of TNFR2-mediated cellular and molecular mechanisms. We specifically emphasize how tumor progression is accelerated after TNFR2 activation on tumor and immune cells within a tumor and briefly discuss the outcome of treatments targeting TNFR2.

\section{TNF RECEPTOR 1 AND TNF RECEPTOR 2}

TNF receptor 1 ( $\mathrm{p} 55$ or CD120a) and TNFR2 (p75 or CD120b) are type I transmembrane receptors. TNFR1 shows extensive expression, whereas TNFR2 expression is limited to immune cells and a few other cell types $(7,9,10)$. TNFR1 and TNFR2 have similar extracellular TNF-binding structures characterized by four repeated cysteine-rich domains (CRDs) (CRD1 also called pre-ligand binding assembly domain, CRD2, CRD3, and CRD4) but have different intracellular domains $(11,12)$. Most critical for the diverse biological effects of the two receptor subtypes is the lack of the intracellular death domain in TNFR2. Hence, TNF promotes apoptosis via binding to TNFR1 but exerts prosurvival effects via TNFR2 $(4,5,13)$. After being engaged by extracellular TNF, TNFR1 recruits and clusters the adaptor protein TNFR1-associated death domain protein (TRADD) and the 
TABLE 1 | Tumor development promoted by TNFR2-mediated signaling in tumor or tumor-associated cells.

\section{Cancer type Impacts of TNF receptor 2 (TNFR2) expression on various cells \\ Breast cancer Promoting tumor cell growth (49); inhibiting programmed death of tumor cells (48); stabilizing myeloid-derived suppressor cells (MDSC) (91); and relating to suppressive function of regulatory $\mathrm{T}\left(\mathrm{T}_{\text {reg }}\right)$ cells (82) \\ Colon cancer Advancing carcinogenesis of epithelia cells (59-61); promoting tumor cell proliferation $(55,56)$; enhancing angiogenesis by upregulating VEGF-A in tumor cells (56); inducing cancer- associated fibroblasts (100); activating $T_{\text {reg }}$ cells $(78,105)$; and supporting metastasis (92) \\ Cervical cancer Facilitating tumorigenesis (58) \\ Fibrosarcoma Promoting MDSC accumulation (85) \\ Liver cancer Expanding $T_{\text {reg }}$ cells (78) and promoting tumoral accumulation of MDSC by inducing specific chemokine receptor (87) \\ Lung cancer Helping to form metastasis niche by stabilizing MDSC (92); promoting VEGF release and anti-apoptotic ability of tumor cells $(50,51)$; and associating with inhibitory effects of $T_{\text {reg }}$ cells $(67,82)$ \\ Melanoma Maintaining $T_{\text {reg }}$ cells (71); contributing to $T$ cell exhaustion (80) \\ Ovarian cancer Acting as oncogene in tumor cells (104); expanding $T_{\text {reg }}$ cells (104); and promoting $T_{\text {reg }}$ cells to impair T-helper 1 immunity (77) \\ Renal cancer Driving proliferation of tumor stem cells (54) and accelerating tumor cell division $(53,79)$ \\ Skin cancer Advancing malignant transformation of epidermal cells (40) \\ Plasmacytoma Driving MDSC expansion (85) \\ Lymphoma Enhancing angiogenesis by inducing interleukin-6 secretion from malignant cells (52) and augmenting activation-induced death of cytotoxic T cells (79) \\ Leukemia Relating to $T_{\text {reg }}$ cell expansion $(102,103)$}

References exploring biological functions of TNFR2 in tumorigenesis, tumor progression, anti-apoptosis, or non-specified other processes in human cancer and murine tumor models within the last 10 years.

downstream caspases (14-16). This finally leads to programmed cell death. In contrast, activated TNFR2 results in recruitment of the TNF receptor-associated factor (TRAF) 2 and stimulates the pro-survival nuclear factor (NF)- $\kappa \mathrm{B}$ pathway (17). TNFR2 has a high affinity to membrane-bound TNF and can deliver TNF to TNFR1 (18-21). Only by this cooperation, TNFR2 can feed a cell to its death (22).

\section{TNF RECEPTORS AND THE COMMON NUCLEAR FACTOR- $\kappa B$ (NF- $\kappa B$ ) PATHWAY}

Nuclear factor- $\kappa \mathrm{B}$ is activated by both TNF receptor subtypes. Upon stimulation by its ligands including TNF $\alpha$ or lymphotoxin, TNFR1 forms a complex with the adaptor TRADD at the plasma membrane $(23,24)$. TRAF2 is transported and clustered into the complex that recruits the cellular inhibitor of apoptosis 1 and 2 (cIAP1/2) proteins (25-27). Together with TRAF2, cIAP1/2 proteins degrade the TRADD-bound ubiquitinated receptor interacting protein (RIP) 1. Multiple ubiquitination of RIP1 and the NF- $\kappa \mathrm{B}$ essential modulator [NEMO; also called I $\kappa \mathrm{B}$ kinase (IKK) $\gamma$ ] engages the kinase TAK1 to the NEMO-containing IKK complex (5). IKK $\beta$ in the IKK complex becomes phosphorylated and phosphorylates the NF- $\kappa \mathrm{B}$ inhibitor $\mathrm{I} \kappa \mathrm{B} \alpha$ that is subsequently cleaved. Released NF- $\kappa \mathrm{B}$ translocates into the nucleus and induces target gene expression.

The detailed mechanisms of how TNFR2 induces NF- $\mathrm{B}$ remain more elusive. So far, only TRAF2 is clear as the key component. Different from TNFR1, TNFR2 directly interacts with TRAF2 (28). Activated TNFR2 binds to TNFR2 through two conserved intracellular domains, the TRAF2-binding motif SKEE (amino acid residues 402-405) and the C-terminal motif (amino acid residues 425-439) (29, 30). TRAF1 and TRAF3 also associate with TNFR2 directly or via TRAF2 at the two conserved domains (31-33). Genetic manipulation confirmed those two domains as most critical for TNFR2-induced NF- $\kappa$ B activation.

As mentioned above, TNFR1 and TNFR2 have distinct impacts on individual cell fates although they both regulate the outcomes through NF- $\mathrm{BB}$. It is reported that the receptor crosstalk depends on the relative expression of each receptor. At high expression of TNFR1, low amounts of TNFR2 enhance TNFR1induced NF- $\kappa$ B activation (34). In contrast, TNFR2 at high levels effectively competes for TRAF2. Consequently, recruitment to the classical TNFR1 pathway and downstream NF- $\kappa$ B activation is compromised. Concentration and conformation of the ligand TNF are also related with the balance between TNFR1 and TNFR2 signals $(20,35)$. Interestingly, a crosstalk of TNFR1 with TNFR2 strongly affects the cell fate decision. When both TNF receptor isotypes are co-expressed, specific activation of TNFR1 leads to continuous expression of anti-apoptotic factors and barely induced apoptotic pathways. Here, cell death is due to the loss of anti-apoptotic factor expression after TNFR2dependent TRAF2 degradation and abrogated recruitment of cIAP1/2 to TNFR1 (36-38). If both receptors are activated at same time, the balanced signal transduction of TNFR1 and TNFR2 leads to cell survival $(39,40)$. The TNFR1-TNFR2 crosstalk is context- and time-dependent, and their intricacy clearly needs further exploration.

\section{TNFR2 PROMOTING TUMORIGENESIS AND PROGRESSION}

TNF receptor 2 is implicated in the occurrence and growth of tumors, therapeutic responses, and patients' prognosis (41-43). In direct and indirect manners, TNFR2 plays important roles in multiple aspects of tumor progression, including the proliferation of tumor cells, the evasion of immune surveillance, the activation of endothelia cells and angiogenesis, and the formation of a premetastasis milieu (Figure 1).

\section{TNFR2 on Tumor Cells and Non-Immune Cells in the Tumor Microenvironment}

Several studies have indicated that TNFR2 expression in tumor tissues relates to advanced disease progression and poor clinical outcomes (44-46). TNFR2 is aberrantly expressed on several types of tumor cells (47) and induces tumor progression through several signal transduction cascades (Figure 2). In breast cancer, TNFR2 protects malignant cells from DNA damage via the AKT 


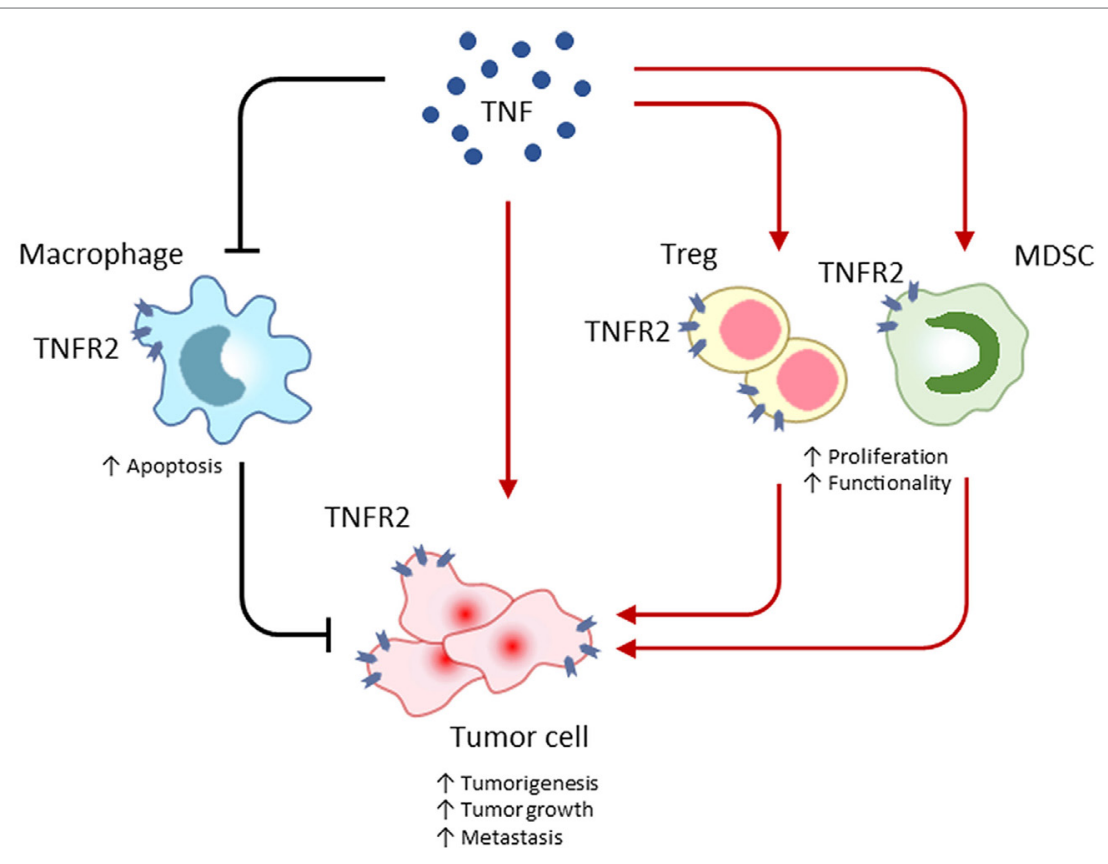

FIGURE 1 | TNF receptor 2 (TNFR2) promotes tumor progression by maintaining a tumor-favoring immune-microenvironment or by facilitating malignant cell proliferation and survival. In the tumor microenvironment, TNFR2 is extensively expressed on many types of cells, including immune cells and malignant cells. TNFR2 often accelerates the malignant transformation and growth of tumor cells, instead of inducing cell death by apoptosis. Similar to tumor cells, TNFR2 protects immunosuppressive regulatory $\mathrm{T}\left(\mathrm{T}_{\text {reg }}\right)$ cells and myeloid-derived suppressor cells (MDSC) from the death-inducing TNF and consequently enhances proliferation and function of those tumor-promoting cells. Even worse, TNFR2 deteriorates the programmed death of phagocytic macrophages responsible for clearing of tumor cells. Mediating those direct and indirect effects, TNFR2 exacerbates cancer progression.

signaling pathway (48) and induces NF-кB via p42/p44 mitogenactivated protein kinase (MAPK) to accelerate tumor cell growth (49). Interestingly, blocking TNFR2 is sufficient to diminish TNFevoked cell growth (49), indicating TNFR2 as more important for tumor progression than the activation of signal kinases including p42/p44 MAPK, JNK, and AKT via the ubiquitous TNFR1. Underlining this, loss of TNFR2 results in a large increase of TNF-associated tumor cell death and a significant halt of tumor growth in lung cancer (50).

TNF receptor 2 deficiency in a mouse model of lung cancer not only enhances tumor cell apoptosis but also leads to downregulated pro-angiogenic factors, like vascular endothelial, hepatocyte, and placental growth factors from endothelial progenitor cells (51). Pointing to a general role for TNFR2 in tumor development, TNFR2-deficient mice decrease melanoma cell growth in the same way (51). Additionally, TNFR2 signaling indirectly promotes angiogenesis by inducing interleukin (IL)-6 secretion (52). In renal carcinoma, TNFR2 on endothelial and tubular epithelial cells activates the endothelial/epithelial tyrosine kinase and then upregulates vascular endothelial growth factor receptor-2 (53) or directly promotes cell division (54). Consequently, expression of TNFR2, but not of TNFR1, correlates with the grading of malignancy. In colorectal carcinoma, TNFR2 promotes tumor cell proliferation through the PI3K-AKT pathway $(55,56)$ or via NF- $\kappa \mathrm{B}$ activation (57). These studies imply that TNFR2 directly enhances tumor growth, but TNFR2 is also involved in malignant transformation (58). In animal models of chronic inflammation,
TNFR2 induces NF- $\kappa \mathrm{B}$ activation in epithelial cells that subsequently leads to carcinogensis (59-61).

\section{TNFR2 on T Cells}

TNF receptor 2 not only affects tumor cells but also regulates tumor-infiltrating immune cells. The resulting immunosuppressive microenvironment supports tumor development. Regulatory $\mathrm{T}\left(\mathrm{T}_{\text {reg }}\right)$ cells are the central player in regulating tumor-specific immune responses (62-64). Hence, $\mathrm{T}_{\text {reg }}$ cells also represent the most important tumor-promoting cell type and are most extensively studied. TNFR2 expressed on $\mathrm{T}_{\text {reg }}$ cells indicates the maximally suppressive subset $(47,65-68)$ and relates to poor prognosis of patients (69). TNFR2 mediates the effects of TNF on $\mathrm{CD}^{+}$forkhead box (Fox)P3 ${ }^{+} \mathrm{T}_{\text {reg }}$ cells $(70,71)$. TNFR2 promotes the development of $\mathrm{T}_{\text {reg }}$ cells in thymus (72), the expansion of differentiated $\mathrm{T}_{\text {reg }}$ cells (73), and mediates the activation effects of TNF on $\mathrm{T}_{\text {reg }}$ cells $(70,71)$. It leads to activation, expansion, and phenotypic stability of the strongly suppressive $\mathrm{T}$ cells (74), partially through an epigenetic mechanism that demethylates the Foxp3 gene (75). TNFR2 is highly expressed on resting and activated $\mathrm{T}_{\text {reg }}$ cells compared to their FoxP3- counterparts (65). TNF expands the TNFR2 ${ }^{+} \mathrm{T}_{\text {reg }}$ subset and augments the IL-2-induced induction of signal transducer and activator of transcription-5 to increase the suppressive function. Consistently, TNFR2 ${ }^{+} \mathrm{T}_{\text {reg }}$ cells comprise the most highly suppressive subset of $\mathrm{T}_{\text {reg }}$ cells (67). $\mathrm{T}_{\text {reg }}$ cells within the tumor microenvironment show higher expression of TNFR2 than $\mathrm{T}_{\text {reg }}$ cells from normal tissues or the periphery (76). 


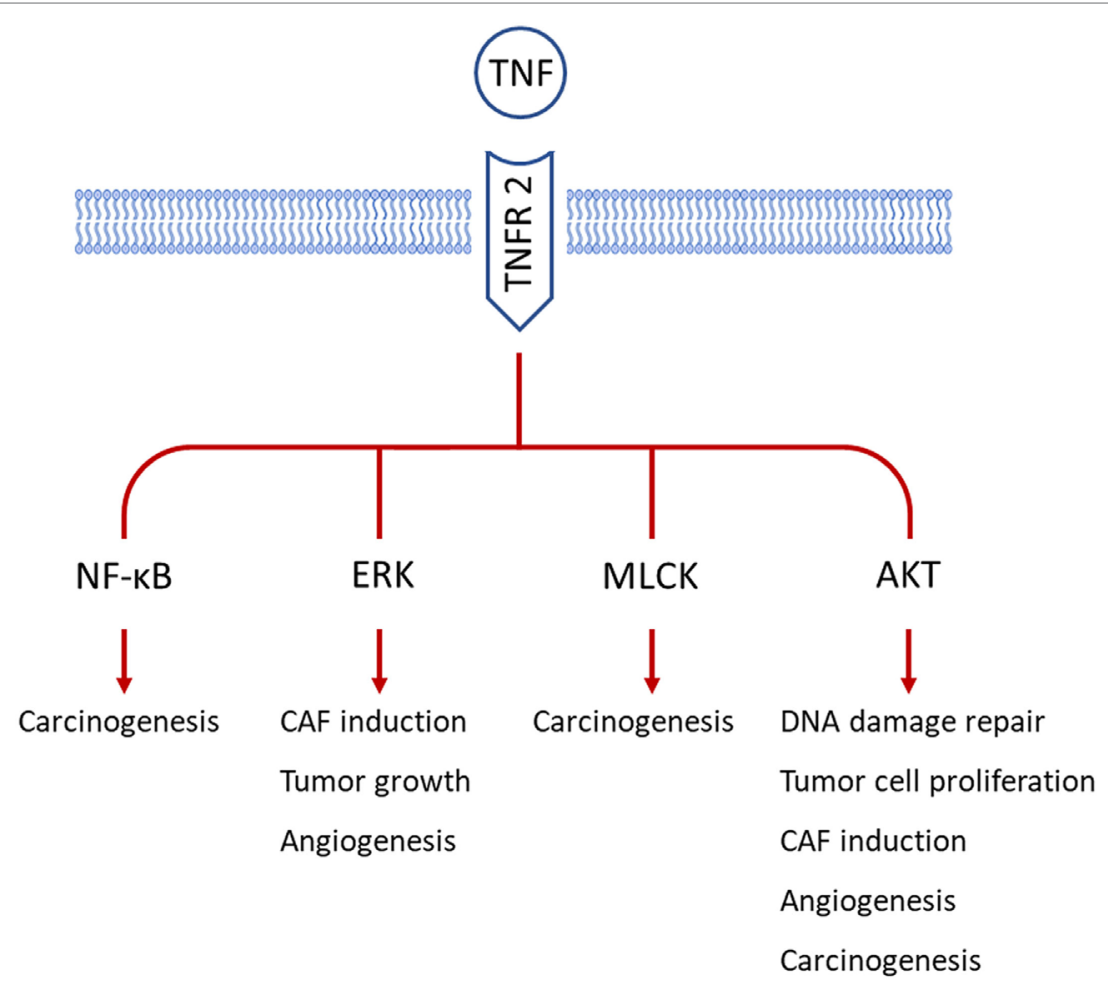

FIGURE 2 | TNF receptor 2 (TNFR2) participates in various processes of tumor development by employing different signal pathways in tumor cells. So far, TNFR2 is reported to be expressed on tumor cells from breast cancer, cervical cancer, colon cancer, and renal cancer. AKT signaling is the major mediator of TNFR2 in carcinogenesis, tumor growth, angiogenesis, and cancer-associated fibroblast (CAF) induction. Besides, myosin light-chain kinase (MLCK) and nuclear factor- $\mathrm{B}$ (NF-кB) are involved in TNFR2-related malignant transformation of epithelial cells. Extracellular signal-regulated kinase (ERK) is also important for the abovementioned functions of TNFR2.

Emphasizing the clinical relevance of those findings in mouse models, $\mathrm{T}_{\text {reg }}$ cells infiltrating human tumors have high levels of TNFR2 expression and maximal suppressive capacity (77). Increased TNFR2 in $\mathrm{T}_{\text {reg }}$ cells enhances TNF-dependent $\mathrm{T}_{\text {reg }}$-cell proliferation and suppressive effects in tumors susceptible to anti-TNF treatment (78). In lung cancer patients, expression of TNFR2 strongly correlates with the transcription factor FoxP3 than the expression of CD25 (69). TNFR2 expression levels on $\mathrm{T}_{\text {reg }}$ cells closely associate with lymphatic invasion, distant metastasis, and advanced clinical stage (69). This not only underlines the functional importance of effective $\mathrm{T}_{\text {reg }}$ cell-mediated control of tumor-specific immune responses but also suggests TNFR2 as a more appropriate marker for tumor-resident $\mathrm{T}_{\text {reg }}$ cells compared to integrin- $\alpha \mathrm{E}$ (CD103) (67).

Taken together, the abundance and strong immunosuppressive capacity point to TNFR2 ${ }^{+} \mathrm{T}_{\text {reg }}$ cells as critical in promoting tumor progression and metastasis.

Although TNFR2 is preferentially expressed on $\mathrm{T}_{\text {reg }}$ cells, the expression of TNFR2 can be induced or up-regulated on CD8 ${ }^{+}$ $\mathrm{T}$ cells and conventional CD4 ${ }^{+} \mathrm{FoxP}^{-}\left(\mathrm{T}_{\text {con }}\right) \mathrm{T}$ cells.

In $\mathrm{CD}^{+} \mathrm{T}$ cells, TNFR2 can elicit activation-induced cell death (79). It also may upregulate the expression of the inhibitory receptor Tim3 (80). Both direct mechanisms further hamper the efficacy of cytotoxic T cells.

Activation of TNFR2 on $\mathrm{T}_{\text {con }}$ cells can lead to enhanced tumoricidal effects (81). TNFR2 on $\mathrm{T}_{\text {con }}$ cells also activates those effector $\mathrm{T}$ cells making them resistant to $\mathrm{T}$ cell-mediated suppression (82). However, $\mathrm{T}_{\text {reg }}$ cells within the tumor microenvironment demonstrate much higher expression levels of TNFR2 that overcome this resistance and maintain the local dominance of immunosuppression (77).

\section{TNFR2 on Myeloid-Derived Suppressor Cells (MDSC)}

Myeloid-derived suppressor cells are a heterogeneous population of immature myeloid cells mainly characterized by their strong immunosuppressive capacity. In healthy individuals, myeloid cells outside the bone marrow are mainly matured into granulocytes or monocytes $(83,84)$. Lineage-specific differentiation fails in chronic inflammation or malignancy, and this associates with a potent immunosuppressive function in the resulting myeloid cells $(21,85)$. These cells appear in peripheral tissues and also represent an important subset of cells in the tumor microenvironment that promotes tumor growth (83). TNF signaling is believed to be critical for MDSC to accumulate and perpetuate their immature state $(86,87)$. Elevated TNF in an inflammatory milieu augments MDSC accumulation and immunosuppression, whereas TNF antagonists reduce the inhibitory function of MDSC and support differentiation into dendritic cells or macrophages (88). 
The feature of TNF to promote immunosuppression is intimately related to TNFR2. TNFR1 and TNFR2 double-negative mice spontaneously reject implanted tumors. This correlates with decreased accumulation of MDSC, which is mainly mediated by TNFR2, but not by TNFR1 (85). TNFR2-mediated signaling increases the induction of MDSC from bone marrow cells and inhibits the apoptosis of MDSC through c-FLIP upregulation and caspase- 8 inhibition. TNFR2 also directs the suppressive functions of MDSC (89). In monocytic MDSC, TNFR2 deficiency compromises the development of MDSC and reduces the production of immunosuppressive factors, like NO and IL-6 (89). Additionally, TNFR2 is important for the production of the immunosuppressive factors, IL-10 and transforming growth factor- $\beta(90)$. The p38 MAPK-NF- $\kappa B$ axis is indispensable for the process of TNFR2-transmitted signals in MDSC. Inhibition of this axis in TNFR2 ${ }^{+}$MDSC stimulated with TNF could reverse T-cell suppression (91). The induction of suppression-related markers, including arginase-1, inducible NO synthase, NO, reactive oxygen species, IL-10, and transforming growth factor- $\beta$ clearly correlates with the activation of the p38MAPK-NF- $\kappa \mathrm{B}$ pathway via TNFR2 (91). All reports support the assumption that TNFR2 promotes primary tumor growth by maintaining the naive state and enhancing the suppressive character of MDSC to control tumor-specific T-cell responses.

TNF receptor 2-expressing MDSC also contribute to metastasis. TNFR2 deficiency reduces the liver metastasis of lung cancer (92). In a mouse model, TNFR2 ${ }^{-/-}$MDSC fail to accumulate in pre-metastatic lesions and show reduced expression of the suppressive arginase-1. Of note, the loss of TNFR2 also alleviates $\mathrm{T}_{\text {reg-cell infiltration into metastasis sites of human lung cancer }}$ (92). We conclude that TNFR2 coordinates $\mathrm{T}_{\text {reg }}$ cells and MDSC in original tumor growth as well as in metastasis.

\section{TNFR2 on Macrophages}

Macrophages are the most dominant innate immune cell type in tumor control, and they are the main sources of TNF (93). Macrophages also simultaneously express TNFR1 and TNFR2, although the effects of TNFR2 on macrophages remain unclear. Similar to the immature MDSC, activation of TNFR2 on macrophages induces the p38 MAPK-NF- $\mathrm{BB}$ pathway (94). TNFR2 on tumor-associated macrophages correlates with malignancy grades in human triple-negative breast cancer and is thought to participate in metastasis (95).

Prompting to the significance of TNF receptor crosstalk discussed above, the TNFR2 also takes part in inducing macrophage death by necroptosis upon TNF-induced TNFR1 activation upon contact with pathogen (22). Without TNFR2 signaling, the induced necroptosis is reversed. Although not shown so far for tumors, TNF-related macrophage death may represent an alternative way of how TNFR2 signaling in macrophages might contribute to tumor progression.

\section{TARGETING TNFR2 FOR TUMOR THERAPY}

TNF receptor 2 is mainly expressed on malignant cells and in the immunosuppressive cell compartment within the tumor microenvironment. It is involved in promoted tumor development and facilitated metastasis. Hence, TNFR2 represents an attractive target for tumor treatment.

Specifically, blocking the ligand TNF is one option. Due to the higher expression of TNFR2 relative to TNFR1 in tumor and tumor-associated cells, TNF is likely to have a tumor-promoting function instead of an inhibitory impact. TNF ablation effectively reduces tumor growth (96).

Of note, activating TNFR2 on tumor-promoting cell types, such as fibroblasts might limit tumor cell invasion and metastasis and improve tumor therapy (97-100).

Depleting TNFR2 ${ }^{+} \mathrm{T}_{\text {reg }}$ cells augmented the efficacy of chemotherapy in preclinical studies (101). In a clinical trial with acute myeloid leukemia patients, patients received the demethylating agent, azacitidine, and the histone deacetylase inhibitor, panobinostat, which effectively eliminated TNFR2 ${ }^{+} \mathrm{T}_{\text {reg }}$ cells in peripheral blood and bone marrow (102). These TNFR2 ${ }^{+} \mathrm{T}_{\text {reg }}$ cells were earlier found as potent suppressive immune cell subset with enhanced migratory ability that promote disease progression and hamper tumor therapy $(65,102)$. Beneficial clinical responses came from more active effector $\mathrm{T}$ cells as determined from increased production of interferon $-\gamma$ and IL-2. A combination of azacitidine with lenalidomide decreasing TNFR2 expression and activity in $\mathrm{T}_{\text {reg }}$ cells may improve clinical outcomes in hematological malignancies (103).

More recently, antibodies specifically blocking TNFR2 were developed for tumor therapy. TNFR2 is abundant on tumor cells and tumor-infiltrating $\mathrm{T}_{\text {reg }}$ cells in ovarian cancer (104). Here, antagonistic antibodies to TNFR2 suppress TNF-induced $\mathrm{T}_{\text {reg- }}$ cell activation and reduce amount as well as immunosuppressive function of $\mathrm{T}_{\text {reg }}$ cells (104). They inhibit NF- $\mathrm{\kappa B}$ activation, hence the $\mathrm{T}_{\text {reg }}$ cell expansion and immunosuppression but synergistically directly induce tumor-cell death (104). This study showed that targeting TNFR2 on $\mathrm{T}_{\text {reg }}$ cells was well tolerated. It mostly affected the tumor-infiltrating $\mathrm{T}_{\text {reg }}$ cells that express much higher levels of TNFR2 than normal $\mathrm{T}_{\text {reg }}$ cells. A concomitant administration of TNFR2-neutralizing antibody and a toll-like receptor agonist has the potential to further improve the therapeutic effectiveness (105).

\section{CONCLUDING REMARKS}

A strongly immunosuppressive microenvironment is a major obstacle in tumor therapy. Over the last decade, immunotherapies using checkpoint blockade and engineered $\mathrm{T}$ cells have gained great success. However, many patients fail to benefit from these therapies. One important reason for the ineffectiveness is the focus on evoking cytotoxic T-cell responses that overlooks the impact of the immunosuppressive cell compartment. Therapy-related changes in the tumor environment often enhance immunosuppressive effects and finally result in a failure of therapy. Considering this, we need to emphasize the immunosuppressive cells and factors in tumor treatment. Here, TNF and its diverse effects mediated by TNFR1 or TNFR2 provide a clue.

Tumor necrosis factor is abundant in any tumor microenvironment. This cytokine is usually involved in anti-tumor 
responses. However, TNFR2 may convert the anti-tumor effect into tumor-promoting function. TNFR2 expression is limited to several cell types that include tumor and immune cells (Figure 1). Tumor cells highly expressing TNFR2 resist TNF-induced cell death via binding of the ligand to the TNFR2. TNFR2 is not only highly expressed on tumor cells but also on immunosuppressive cells, including $\mathrm{T}_{\text {reg }}$ cells and MDSC. Thus, TNFR2 is tightly related with the immunoinhibitory capacities of tumor-promoting cells.

All these specific properties of TNFR2 make it an ideal candidate for targeted tumor therapy. Several studies targeting TNFR2 already proved its great potential in treating tumor. Future investigations will provide more detailed knowledge on all facets and on the cell-type dependency of TNFR2's immunosuppressive

\section{REFERENCES}

1. Balkwill F. Tumour necrosis factor and cancer. Nat Rev Cancer (2009) 9:361-71. doi: $10.1038 / \mathrm{nrc} 2628$

2. Sethi G, Sung B, Aggarwal BB. TNF: a master switch for inflammation to cancer. Front Biosci (2008) 13:5094-107. doi:10.2741/3066

3. Martinez-Reza I, Diaz L, Garcia-Becerra R. Preclinical and clinical aspects of TNF-alpha and its receptors TNFR1 and TNFR2 in breast cancer. J Biomed Sci (2017) 24:90. doi:10.1186/s12929-017-0398-9

4. Ham B, Fernandez MC, D'Costa Z, Brodt P. The diverse roles of the TNF axis in cancer progression and metastasis. Trends Cancer Res (2016) 11:1-27.

5. Brenner D, Blaser H, Mak TW. Regulation of tumour necrosis factor signalling: live or let die. Nat Rev Immunol (2015) 15:362-74. doi:10.1038/nri3834

6. Kuprash DV, Qin Z, Ito D, Grivennikov SI, Abe K, Drutskaya LN, et al. Ablation of TNF or lymphotoxin signaling and the frequency of spontaneous tumors in p53-deficient mice. Cancer Lett (2008) 268:70-5. doi:10.1016/j.canlet. 2008.03.023

7. Speeckaert MM, Speeckaert R, Laute M, Vanholder R, Delanghe JR. Tumor necrosis factor receptors: biology and therapeutic potential in kidney diseases. Am J Nephrol (2012) 36:261-70. doi:10.1159/000342333

8. Hagemann T, Wilson J, Kulbe H, Li NF, Leinster DA, Charles K, et al. Macrophages induce invasiveness of epithelial cancer cells via NF-kappa B and JNK. JImmunol (2005) 175:1197-205. doi:10.4049/ jimmunol.175.2.1197

9. Clouthier DL, Watts TH. TNFRs and control of chronic LCMV infection: implications for therapy. Trends Immunol (2015) 36:697-708. doi:10.1016/j. it.2015.09.005

10. Liu S, Rong L, Deng J, Zhao X, Liu X, Xu X, et al. TNFR2 expression on non-bone marrow-derived cells is crucial for lipopolysaccharide-induced septic shock and downregulation of soluble TNFR2 level in serum. Cell Mol Immunol (2011) 8:164-71. doi:10.1038/cmi.2010.79

11. Park YH, Jeong MS, Jang SB. Structural insights of homotypic interaction domains in the ligand-receptor signal transduction of tumor necrosis factor (TNF). BMB Rep (2016) 49:159-66. doi:10.5483/BMBRep.2016. 49.3.205

12. Al-Lamki RS, Mayadas TN. TNF receptors: signaling pathways and contribution to renal dysfunction. Kidney Int (2015) 87:281-96. doi:10.1038/ ki.2014.285

13. Shivakumar P, Mizuochi T, Mourya R, Gutta S, Yang L, Luo Z, et al. Preferential TNFalpha signaling via TNFR2 regulates epithelial injury and duct obstruction in experimental biliary atresia. JCI Insight (2017) 2:e88747. doi: $10.1172 /$ jci.insight. 88747

14. Hsu H, Xiong J, Goeddel DV. The TNF receptor 1-associated protein TRADD signals cell death and NF-kappa B activation. Cell (1995) 81:495-504. doi:10.1016/0092-8674(95)90070-5

15. Huang J, Yu S, Ji C, Li J. Structural basis of cell apoptosis and necrosis in TNFR signaling. Apoptosis (2015) 20:210-5. doi:10.1007/s10495-014-1061-5

16. Aggarwal BB, Gupta SC, Kim JH. Historical perspectives on tumor necrosis factor and its superfamily: 25 years later, a golden journey. Blood (2012) 119:651-65. doi:10.1182/blood-2011-04-325225 effects that we need to translate it into the treatment of malignant diseases.

\section{AUTHOR CONTRIBUTIONS}

YS, FL, and ZQ wrote the manuscript; ZQ critically revised the manuscript.

\section{ACKNOWLEDGMENTS}

This work was supported by National Natural Science Foundation of China (81630068, 31670881, and 81502628). We thank Ulrike Erben for her careful reading of the manuscript and thorough editing of the language.

17. Rothe M, Sarma V, Dixit VM, Goeddel DV. TRAF2-mediated activation of NF-kappa B by TNF receptor 2 and CD40. Science (1995) 269:1424-7. doi:10.1126/science.7544915

18. Grell M, Douni E, Wajant H, Lohden M, Clauss M, Maxeiner B, et al. The transmembrane form of tumor necrosis factor is the prime activating ligand of the $80 \mathrm{kDa}$ tumor necrosis factor receptor. Cell (1995) 83:793-802. doi:10.1016/0092-8674(95)90192-2

19. Gao H, Danzi MC, Choi CS, Taherian M, Dalby-Hansen C, Ellman DG, et al. Opposing functions of microglial and macrophagic TNFR2 in the pathogenesis of experimental autoimmune encephalomyelitis. Cell Rep (2017) 18:198-212. doi:10.1016/j.celrep.2016.11.083

20. Qu Y, Zhao G, Li H. Forward and reverse signaling mediated by transmembrane tumor necrosis factor-alpha and TNF receptor 2: potential roles in an immunosuppressive tumor microenvironment. Front Immunol (2017) 8 1675. doi:10.3389/fimmu.2017.01675

21. Chavez-Galan L, Vesin D, Uysal H, Blaser G, Benkhoucha M, Ryffel B, et al. Transmembrane tumor necrosis factor controls myeloid-derived suppressor cell activity via TNF receptor 2 and protects from excessive inflammation during BCG-induced pleurisy. Front Immunol (2017) 8:999. doi:10.3389/ fimmu.2017.00999

22. Siegmund D, Kums J, Ehrenschwender M, Wajant H. Activation of TNFR2 sensitizes macrophages for TNFR1-mediated necroptosis. Cell Death Dis (2016) 7:e2375. doi:10.1038/cddis.2016.285

23. Micheau O, Tschopp J. Induction of TNF receptor I-mediated apoptosis via two sequential signaling complexes. Cell (2003) 114:181-90. doi:10.1016/ S0092-8674(03)00521-X

24. Hsu H, Shu HB, Pan MG, Goeddel DV. TRADD-TRAF2 and TRADD-FADD interactions define two distinct TNF receptor 1 signal transduction pathways. Cell (1996) 84:299-308. doi:10.1016/S0092-8674(00)80984-8

25. Vince JE, Pantaki D, Feltham R, Mace PD, Cordier SM, Schmukle AC, et al. TRAF2 must bind to cellular inhibitors of apoptosis for tumor necrosis factor (tnf) to efficiently activate $\mathrm{nf}-\{$ kappa $\} \mathrm{b}$ and to prevent tnf-induced apoptosis J Biol Chem (2009) 284:35906-15. doi:10.1074/jbc.M109.072256

26. Haas TL, Emmerich CH, Gerlach B, Schmukle AC, Cordier SM, Rieser E, et al. Recruitment of the linear ubiquitin chain assembly complex stabilizes the TNF-R1 signaling complex and is required for TNF-mediated gene induction. Mol Cell (2009) 36:831-44. doi:10.1016/j.molcel.2009.10.013

27. Park YC, Ye H, Hsia C, Segal D, Rich RL, Liou HC, et al. A novel mechanism of TRAF signaling revealed by structural and functional analyses of the TRADD-TRAF2 interaction. Cell (2000) 101:777-87. doi:10.1016/ S0092-8674(00)80889-2

28. Borghi A, Verstrepen L, Beyaert R. TRAF2 multitasking in TNF receptorinduced signaling to NF-kappaB, MAP kinases and cell death. Biochem Pharmacol (2016) 116:1-10. doi:10.1016/j.bcp.2016.03.009

29. Rodriguez M, Cabal-Hierro L, Carcedo MT, Iglesias JM, Artime N, Darnay BG, et al. NF-kappaB signal triggering and termination by tumor necrosis factor receptor 2. J Biol Chem (2011) 286:22814-22824. doi:10.1074/jbc. M111.225631

30. Grech AP, Gardam S, Chan T, Quinn R, Gonzales R, Basten A, et al. Tumor necrosis factor receptor 2 (TNFR2) signaling is negatively regulated by a 
novel, carboxyl-terminal TNFR-associated factor 2 (TRAF2)-binding site. J Biol Chem (2005) 280:31572-31581.

31. Cabal-Hierro L, Rodriguez M, Artime N, Iglesias J, Ugarte L, Prado MA, et al. TRAF-mediated modulation of NF-kB AND JNK activation by TNFR2. Cell Signal (2014) 26:2658-66. doi:10.1016/j.cellsig.2014.08.011

32. Rothe M, Wong SC, Henzel WJ, Goeddel DV. A novel family of putative signal transducers associated with the cytoplasmic domain of the $75 \mathrm{kDa}$ tumor necrosis factor receptor. Cell (1994) 78:681-92. doi:10.1016/0092-8674(94) 90532-0

33. Zheng C, Kabaleeswaran V, Wang Y, Cheng G, Wu H. Crystal structures of the TRAF2: CIAP2 and the TRAF1: TRAF2: cIAP2 complexes: affinity, specificity, and regulation. Mol Cell (2010) 38:101-13. doi:10.1016/j.molcel. 2010.03.009

34. Cabal-Hierro L, Artime N, Iglesias J, Prado MA, Ugarte-Gil L, Casado P, et al. A TRAF2 binding independent region of TNFR2 is responsible for TRAF2 depletion and enhancement of cytotoxicity driven by TNFR1. Oncotarget (2014) 5:224-36. doi:10.18632/oncotarget.1492

35. Marchetti L, Klein M, Schlett K, Pfizenmaier K, Eisel UL. Tumor necrosis factor (TNF)-mediated neuroprotection against glutamate-induced excitotoxicity is enhanced by $\mathrm{N}$-methyl-D-aspartate receptor activation. Essential role of a TNF receptor 2-mediated phosphatidylinositol 3-kinase-dependent NF-kappa B pathway. J Biol Chem 279(2004):32869-32881. doi:10.1074/jbc. M311766200

36. Wicovsky A, Henkler F, Salzmann S, Scheurich P, Kneitz C, Wajant H. Tumor necrosis factor receptor-associated factor- 1 enhances proinflammatory TNF receptor-2 signaling and modifies TNFR1-TNFR2 cooperation. Oncogene (2009) 28:1769-81. doi:10.1038/onc.2009.29

37. Carpentier I, Beyaert R. TRAF1 is a TNF inducible regulator of NF-kappaB activation. FEBSLett(1999) 460:246-50. doi:10.1016/S0014-5793(99)01356-3

38. Rauert H, Stuhmer T, Bargou R, Wajant H, Siegmund D. TNFR1 and TNFR2 regulate the extrinsic apoptotic pathway in myeloma cells by multiple mechanisms. Cell Death Dis (2011) 2:e194. doi:10.1038/cddis.2011.78

39. Fotin-Mleczek M, Henkler F, Samel D, Reichwein M, Hausser A, Parmryd I, et al. Apoptotic crosstalk of TNF receptors: TNF-R2-induces depletion of TRAF2 and IAP proteins and accelerates TNF-R1-dependent activation of caspase-8. J Cell Sci (2002) 115:2757-70.

40. Arnott CH, Scott KA, Moore RJ, Robinson SC, Thompson RG, Balkwill FR. Expression of both TNF-alpha receptor subtypes is essential for optimal skin tumour development. Oncogene (2004) 23:1902-10. doi:10.1038/sj.onc. 1207317

41. Purdue MP, Hofmann JN, Kemp TJ, Chaturvedi AK, Lan Q, Park JH, et al. A prospective study of 67 serum immune and inflammation markers and risk of non-Hodgkin lymphoma. Blood (2013) 122:951-7. doi:10.1182/ blood-2013-01-481077

42. Babic A, Shah SM, Song M, Wu K, Meyerhardt JA, Ogino S, et al. Soluble tumour necrosis factor receptor type II and survival in colorectal cancer. Br J Cancer (2016) 114:995-1002. doi:10.1038/bjc.2016.85

43. Zhang T, Jiao J, Jiao X, Zhao L, Tian X, Zhang Q, et al. Aberrant frequency of TNFR2(+) Treg and related cytokines in patients with CIN and cervical cancer. Oncotarget (2018) 9:5073-83. doi:10.18632/oncotarget.23581

44. Cui LF, Guo XJ, Wei J, Liu FF, Fan Y, Lang RG, et al. Overexpression of TNF-alpha and TNFRII in invasive micropapillary carcinoma of the breast: clinicopathological correlations. Histopathology (2008) 53:381-8. doi:10.1111/j.1365-2559.2008.03128.x

45. Dobrzycka B, Terlikowski SJ, Garbowicz M, Niklinska W, Bernaczyk PS, Niklinski J, et al. Tumor necrosis factor-alpha and its receptors in epithelial ovarian cancer. Folia Histochem Cytobiol (2009) 47:609-13. doi:10.2478/ v10042-008-0117-1

46. Yang F, Zhao Z, Zhao N. Clinical implications of tumor necrosis factor receptor 2 in breast cancer. Oncol Lett (2017) 14:2393-8. doi:10.3892/ ol.2017.6410

47. Vanamee ES, Faustman DL. TNFR2: a novel target for cancer immunotherapy. Trends Mol Med (2017) 23:1037-46. doi:10.1016/j.molmed. 2017.09.007

48. Yang F, Zhao N, Wu N. TNFR2 promotes Adriamycin resistance in breast cancer cells by repairing DNA damage. Mol Med Rep (2017) 16:2962-8. doi:10.3892/mmr.2017.6898

49. Rivas MA, Carnevale RP, Proietti CJ, Rosemblit C, Beguelin W, Salatino M, et al. TNF alpha acting on TNFR1 promotes breast cancer growth via p42/
P44 MAPK, JNK, Akt and NF-kappa B-dependent pathways. Exp Cell Res (2008) 314:509-29. doi:10.1016/j.yexcr.2007.10.005

50. Sasi SP, Bae S, Song J, Perepletchikov A, Schneider D, Carrozza J, et al. Therapeutic non-toxic doses of TNF induce significant regression in TNFR2-p75 knockdown Lewis lung carcinoma tumor implants. PLoS One (2014) 9:e92373. doi:10.1371/journal.pone.0092373

51. Sasi SP, Yan X, Enderling H, Park D, Gilbert HY, Curry C, et al. Breaking the 'harmony' of TNF-alpha signaling for cancer treatment. Oncogene (2012) 31:4117-27. doi:10.1038/onc.2011.567

52. Lauenborg B, Christensen L, Ralfkiaer U, Kopp KL, Jonson L, Dabelsteen S, et al. Malignant $\mathrm{T}$ cells express lymphotoxin alpha and drive endothelial activation in cutaneous T cell lymphoma. Oncotarget (2015) 6:15235-49. doi:10.18632/oncotarget.3837

53. Al-Lamki RS, Sadler TJ, Wang J, Reid MJ, Warren AY, Movassagh M, et al. Tumor necrosis factor receptor expression and signaling in renal cell carcinoma. Am J Pathol (2010) 177:943-54. doi:10.2353/ajpath.2010. 091218

54. Al-Lamki RS, Wang J, Yang J, Burrows N, Maxwell PH, Eisen T, et al. Tumor necrosis factor receptor 2-signaling in CD133-expressing cells in renal clear cell carcinoma. Oncotarget (2016) 7:24111-24. doi:10.18632/ oncotarget. 8125

55. Zhao T, Li H, Liu Z. Tumor necrosis factor receptor 2 promotes growth of colorectal cancer via the PI3K/AKT signaling pathway. Oncol Lett (2017) 13:342-6. doi:10.3892/ol.2016.5403

56. Yang D, Wang LL, Dong TT, Shen YH, Guo XS, Liu CY, et al. Progranulin promotes colorectal cancer proliferation and angiogenesis through TNFR2/ Akt and ERK signaling pathways. Am J Cancer Res (2015) 5:3085-97.

57. Jain SS, Bird RP. Elevated expression of tumor necrosis factor-alpha signaling molecules in colonic tumors of Zucker obese (fa/fa) rats. Int J Cancer (2010) 127:2042-50. doi:10.1002/ijc. 25232

58. Feng T, Zheng L, Liu F, Xu X, Mao S, Wang X, et al. Growth factor progranulin promotes tumorigenesis of cervical cancer via PI3K/Akt/mTOR signaling pathway. Oncotarget (2016) 7:58381-95. doi:10.18632/oncotarget.11126

59. Nagaishi T, Watabe T, Jose N, Tokai A, Fujii T, Matsuoka K, et al. Epithelial nuclear factor-x03BA;B activation in inflammatory bowel diseases and colitis-associated carcinogenesis. Digestion (2016) 93:40-6. doi:10.1159/ 000441670

60. Onizawa M, Nagaishi T, Kanai T, Nagano K, Oshima S, Nemoto Y, et al. Signaling pathway via TNF-alpha/NF-kappaB in intestinal epithelial cells may be directly involved in colitis-associated carcinogenesis. Am J Physiol Gastrointest Liver Physiol (2009) 296:G850-9. doi:10.1152/ajpgi. 00071.2008

61. Suzuki M, Nagaishi T, Yamazaki M, Onizawa M, Watabe T, Sakamaki Y, et al. Myosin light chain kinase expression induced via tumor necrosis factor receptor 2 signaling in the epithelial cells regulates the development of colitis-associated carcinogenesis. PLoS One (2014) 9:e88369. doi:10.1371/ journal.pone.0088369

62. Facciabene A, Motz GT, Coukos G. T-regulatory cells: key players in tumor immune escape and angiogenesis. Cancer Res (2012) 72:2162-71. doi:10.1158/0008-5472.CAN-11-3687

63. Cari L, Nocentini G, Migliorati G, Riccardi C. Potential effect of tumorspecific Treg-targeted antibodies in the treatment of human cancers: a bioinformatics analysis. Oncoimmunology (2018) 7:e1387705. doi:10.1080/ 2162402X.2017.1387705

64. Byrne WL, Mills KH, Lederer JA, O'Sullivan GC. Targeting regulatory T cells in cancer. Cancer Res (2011) 71:6915-20. doi:10.1158/0008-5472. CAN-11-1156

65. Chen X, Baumel M, Mannel DN, Howard OM, Oppenheim JJ. Interaction of TNF with TNF receptor type 2 promotes expansion and function of mouse CD4+CD25+ T regulatory cells. J Immunol (2007) 179:154-61. doi:10.4049/ jimmunol.179.1.154

66. Nguyen DX, Ehrenstein MR. Anti-TNF drives regulatory T cell expansion by paradoxically promoting membrane TNF-TNF-RII binding in rheumatoid arthritis. J Exp Med (2016) 213:1241-53. doi:10.1084/jem.20151255

67. Chen X, Subleski JJ, Kopf H, Howard OM, Mannel DN, Oppenheim JJ. Cutting edge: expression of TNFR2 defines a maximally suppressive subset of mouse CD4+CD25+FoxP3+ T regulatory cells: applicability to tumorinfiltrating T regulatory cells. JImmunol (2008) 180:6467-71. doi:10.4049/ jimmunol.180.10.6467 
68. Chen X, Subleski JJ, Hamano R, Howard OM, Wiltrout RH, Oppenheim JJ. Co-expression of TNFR2 and CD25 identifies more of the functional $\mathrm{CD} 4+\mathrm{FOXP} 3+$ regulatory $\mathrm{T}$ cells in human peripheral blood. Eur J Immunol (2010) 40:1099-106. doi:10.1002/eji.200940022

69. Yan F, Du R, Wei F, Zhao H, Yu J, Wang C, et al. Expression of TNFR2 by regulatory $\mathrm{T}$ cells in peripheral blood is correlated with clinical pathology of lung cancer patients. Cancer Immunol Immunother (2015) 64:1475-85. doi:10.1007/s00262-015-1751-z

70. Chopra M, Biehl M, Steinfatt T, Brandl A, Kums J, Amich J, et al. Exogenous TNFR2 activation protects from acute GvHD via host T reg cell expansion. J Exp Med (2016) 213:1881-900. doi:10.1084/jem.20151563

71. Chopra M, Riedel SS, Biehl M, Krieger S, von Krosigk V, Bauerlein CA, et al. Tumor necrosis factor receptor 2-dependent homeostasis of regulatory $\mathrm{T}$ cells as a player in TNF-induced experimental metastasis. Carcinogenesis (2013) 34:1296-303. doi:10.1093/carcin/bgt038

72. Mahmud SA, Manlove LS, Schmitz HM, Xing Y, Wang Y, Owen DL, et al. Costimulation via the tumor-necrosis factor receptor superfamily couples TCR signal strength to the thymic differentiation of regulatory T cells. Nat Immunol (2014) 15:473-81. doi:10.1038/ni.2849

73. Okubo Y, Mera T, Wang L, Faustman DL. Homogeneous expansion of human T-regulatory cells via tumor necrosis factor receptor 2. Sci Rep (2013) 3:3153. doi: $10.1038 /$ srep 03153

74. Chen X, Wu X, Zhou Q, Howard OM, Netea MG, Oppenheim JJ. TNFR2 is critical for the stabilization of the CD4+Foxp3+ regulatory T. cell phenotype in the inflammatory environment. J Immunol (2013) 190:1076-84. doi:10.4049/jimmunol.1202659

75. Urbano PCM, Koenen H, Joosten I, He X. An autocrine TNFalpha-tumor necrosis factor receptor 2 loop promotes epigenetic effects inducing human Treg stability in vitro. Front Immunol (2018) 9:573. doi:10.3389/fimmu. 2018.00573

76. Kampan NC, Madondo MT, McNally OM, Stephens AN, Quinn MA, Plebanski M. Interleukin 6 present in inflammatory ascites from advanced epithelial ovarian cancer patients promotes tumor necrosis factor receptor 2-expressing regulatory T cells. Front Immunol (2017) 8:1482. doi:10.3389/ fimmu.2017.01482

77. Govindaraj C, Scalzo-Inguanti K, Madondo M, Hallo J, Flanagan K, Quinn M, et al. Impaired Th1 immunity in ovarian cancer patients is mediated by TNFR2+ Tregs within the tumor microenvironment. Clin Immunol (2013) 149:97-110. doi:10.1016/j.clim.2013.07.003

78. Chang LY, Lin YC, Chiang JM, Mahalingam J, Su SH, Huang CT, et al. Blockade of TNF-alpha signaling benefits cancer therapy by suppressing effector regulatory T cell expansion. Oncoimmunology (2015) 4:e1040215. doi:10.1080/2162402X.2015.1040215

79. Kim EY, Teh SJ, Yang J, Chow MT, Teh HS. TNFR2-deficient memory CD8 $\mathrm{T}$ cells provide superior protection against tumor cell growth. JImmunol (2009) 183:6051-7. doi:10.4049/jimmunol.0803482

80. Bertrand F, Montfort A, Marcheteau E, Imbert C, Gilhodes J, Filleron T, et al. TNFalpha blockade overcomes resistance to anti-PD-1 in experimental melanoma. Nat Commun (2017) 8:2256. doi:10.1038/s41467-017-02358-7

81. Williams GS, Mistry B, Guillard S, Ulrichsen JC, Sandercock AM, Wang J, et al. Phenotypic screening reveals TNFR2 as a promising target for cancer immunotherapy. Oncotarget (2016) 7:68278-91. doi:10.18632/oncotarget. 11943

82. Chen X, Hamano R, Subleski JJ, Hurwitz AA, Howard OM, Oppenheim JJ. Expression of costimulatory TNFR2 induces resistance of CD4+FoxP3conventional $\mathrm{T}$ cells to suppression by $\mathrm{CD} 4+\mathrm{FoxP} 3+$ regulatory $\mathrm{T}$ cells. J Immunol (2010) 185:174-82. doi:10.4049/jimmunol.0903548

83. Kumar V, Patel S, Tcyganov E, Gabrilovich DI. The nature of myeloid-derived suppressor cells in the tumor microenvironment. Trends Immunol (2016) 37:208-20. doi:10.1016/j.it.2016.01.004

84. Gabrilovich DI, Ostrand-Rosenberg S, Bronte V. Coordinated regulation of myeloid cells by tumours. Nat Rev Immunol (2012) 12:253-68. doi:10.1038/ nri3175

85. Zhao X, Rong L, Zhao X, Li X, Liu X, Deng J, et al. TNF signaling drives myeloid-derived suppressor cell accumulation. JClin Invest (2012) 122:4094-104. doi:10.1172/JCI64115

86. Sobo-Vujanovic A, Vujanovic L, DeLeo AB, Concha-Benavente F, Ferris RL, Lin $Y$, et al. Inhibition of soluble tumor necrosis factor prevents chemically induced carcinogenesis in mice. Cancer Immunol Res (2016) 4:441-51. doi:10.1158/2326-6066.CIR-15-0104

87. Ba H, Li B, Li X, Li C, Feng A, Zhu Y, et al. Transmembrane tumor necrosis factor-alpha promotes the recruitment of MDSCs to tumor tissue by upregulating CXCR4 expression via TNFR2. Int Immunopharmacol (2017) 44:143-52. doi:10.1016/j.intimp.2016.12.028

88. Sade-Feldman M, Kanterman J, Ish-Shalom E, Elnekave M, Horwitz E, Baniyash M. Tumor necrosis factor-alpha blocks differentiation and enhances suppressive activity of immature myeloid cells during chronic inflammation. Immunity (2013) 38:541-54. doi:10.1016/j.immuni.2013.02.007

89. Polz J, Remke A, Weber S, Schmidt D, Weber-Steffens D, Pietryga-Krieger A, et al. Myeloid suppressor cells require membrane TNFR2 expression for suppressive activity. Immun Inflamm Dis (2014) 2:121-30. doi:10.1002/ iid3.19

90. Xu X, Meng Q, Erben U, Wang P, Glauben R, Kuhl AA, et al. Myeloidderived suppressor cells promote B-cell production of IgA in a TNFR2dependent manner. Cell Mol Immunol (2017) 14:597-606. doi:10.1038/cmi. 2015.103

91. Hu X, Li B, Li X, Zhao X, Wan L, Lin G, et al. Transmembrane TNF-alpha promotes suppressive activities of myeloid-derived suppressor cells via TNFR2. J Immunol (2014) 192:1320-31. doi:10.4049/jimmunol.1203195

92. Ham B, Wang N, D'Costa Z, Fernandez MC, Bourdeau F, Auguste P, et al. TNF receptor-2 facilitates an immunosuppressive microenvironment in the liver to promote the colonization and growth of hepatic metastases. Cancer Res (2015) 75:5235-47. doi:10.1158/0008-5472.CAN-14-3173

93. Parameswaran N, Patial S. Tumor necrosis factor-alpha signaling in macrophages. Crit Rev Eukaryot Gene Expr (2010) 20:87-103. doi:10.1615/ CritRevEukarGeneExpr.v20.i2.10

94. Ruspi G, Schmidt EM, McCann F, Feldmann M, Williams RO, Stoop AA, et al. TNFR2 increases the sensitivity of ligand-induced activation of the p38 MAPK and NF-kappaB pathways and signals TRAF2 protein degradation in macrophages. Cell Signal (2014) 26:683-90. doi:10.1016/j.cellsig. 2013.12.009

95. Frankenberger C, Rabe D, Bainer R, Sankarasharma D, Chada K, Krausz T, et al. Metastasis suppressors regulate the tumor microenvironment by blocking recruitment of prometastatic tumor-associated macrophages. Cancer Res (2015) 75:4063-73. doi:10.1158/0008-5472.CAN-14-3394

96. Atretkhany KS, Nosenko MA, Gogoleva VS, Zvartsev RV, Qin Z, Nedospasov SA, et al. TNF neutralization results in the delay of transplantable tumor growth and reduced MDSC accumulation. Front Immunol (2016) 7:147. doi:10.3389/ fimmu.2016.00147

97. Han S, Ma C, Hu M, Wang Y, Ma F, Tao N, et al. A polysaccharide from Dictyophora indusiata inhibits the immunosuppressive function of cancerassociated fibroblasts. Cell Biochem Funct (2017) 35:414-9. doi:10.1002/ cbf. 3290

98. Zhang J, Chen L, Xiao M, Wang C, Qin Z. FSP1+ fibroblasts promote skin carcinogenesis by maintaining MCP-1-mediated macrophage infiltration and chronic inflammation. Am J Pathol (2011) 178:382-90. doi:10.1016/j. ajpath.2010.11.017

99. Liu J, Kang SG, Wang P, Wang Y, Lv X, Liu Y, et al. Molecular mechanism of Gd@ $\mathrm{C}_{82}(\mathrm{OH})_{22}$ increasing collagen expression: implication for encaging tumor. Biomaterials (2018) 152:24-36. doi:10.1016/j.biomaterials.2017.10.027

100. Wang L, Yang D, Tian J, Gao A, Shen Y, Ren X, et al. Tumor necrosis factor receptor 2/AKT and ERK signaling pathways contribute to the switch from fibroblasts to CAFs by progranulin in microenvironment of colorectal cancer. Oncotarget (2017) 8:26323-33. doi:10.18632/oncotarget.15461

101. van der Most RG, Currie AJ, Mahendran S, Prosser A, Darabi A, Robinson BW, et al. Tumor eradication after cyclophosphamide depends on concurrent depletion of regulatory T cells: a role for cycling TNFR2-expressing effectorsuppressor $\mathrm{T}$ cells in limiting effective chemotherapy. Cancer Immunol Immunother (2009) 58:1219-28. doi:10.1007/s00262-008-0628-9

102. Govindaraj C, Tan P, Walker P, Wei A, Spencer A, Plebanski M. Reducing TNF receptor $2+$ regulatory $\mathrm{T}$ cells via the combined action of azacitidine and the HDAC inhibitor, panobinostat for clinical benefit in acute myeloid leukemia patients. Clin Cancer Res (2014) 20:724-35. doi:10.1158/10780432.CCR-13-1576

103. Govindaraj C, Madondo M, Kong YY, Tan P, Wei A, Plebanski M. Lenalidomide-based maintenance therapy reduces TNF receptor 2 on CD4 
T cells and enhances immune effector function in acute myeloid leukemia patients. Am J Hematol (2014) 89:795-802. doi:10.1002/ajh.23746

104. Torrey H, Butterworth J, Mera T, Okubo Y, Wang L, Baum D, et al. Targeting TNFR2 with antagonistic antibodies inhibits proliferation of ovarian cancer cells and tumor-associated Tregs. Sci Signal (2017) 10(462):eaaf8608. doi:10.1126/scisignal.aaf8608

105. Nie Y, He J, Shirota H, Trivett AL, Yang D, Klinman DM, et al. Blockade of TNFR2 signaling enhances the immunotherapeutic effect of CpG ODN in a mouse model of colon cancer. Sci Signal (2018) 11(511):eaan0790. doi:10.1126/scisignal.aan 0790
Conflict of Interest Statement: The authors declare that the research was conducted in the absence of any commercial or financial relationships that could be construed as a potential conflict of interest.

Copyright $\odot 2018$ Sheng, Li and Qin. This is an open-access article distributed under the terms of the Creative Commons Attribution License (CC BY). The use, distribution or reproduction in other forums is permitted, provided the original author(s) and the copyright owner are credited and that the original publication in this journal is cited, in accordance with accepted academic practice. No use, distribution or reproduction is permitted which does not comply with these terms. 